\title{
Effect of CZTS Parameters on Photovoltaic Solar Cell from Numerical Simulation
}

\author{
Abdellah Benami \\ OTEA, Département de Physique FSTE, Université Moulay Ismail, Boutalamine B.P. 509, Errachidia, Morocco
}

\begin{abstract}
In the present work, we have simulated the structure i-ZnO/n-CdS/p-CZTS/Mo based on copper-zinc-tin-sulphur (CZTS). CZTS has become a candidate material for new photovoltaic solar cell because of its excellent properties. We have used solar cell capacitance simulator one-dimensional (SCAPS-1D) to examine the impact of bandgap and thickness of CZTS on the performance of solar cells. It has been obtained the efficiency of $15.04 \%$ for the optimum thickness of $2,000 \mathrm{~nm}$ and the bandgap of $1.4 \mathrm{eV}$. For the best performance cell $\mathrm{FF}=76.28 \%, J_{\mathrm{sc}}=23.51 \mathrm{~mA} / \mathrm{cm}^{2}$, and $V_{\mathrm{oc}}=0.84 \mathrm{~V}$.
\end{abstract}

Key words: CZTS solar cells, SCAPS-1D, simulation, thin films.

\section{Introduction}

Today, energy is the key element of modern development [1]. Economic development, the environment and energy of a country are closely related. The energy consumption has been increasing as a result of population increases and economic growth worldwide [2].

Fossil fuels are presently the major source of energy consumed worldwide. In 2015, the worldwide total primary energy supply was 13,647 Mtoe and more than $86 \%$ of that energy is on fossil fuels and nuclear [3]. But the fossil fuels are limited available resources and create pollution by emission of carbon dioxide, impurities of arsenic and other heavy metals which are harmful to ecological as well as to human health. So, given the challenges related to climate change and dependency from fossil fuels which increase in prices, there is a growing need for renewable energy sources. Because the most renewable energy comes either directly or indirectly from the sun, photovoltaic (PV) technology is promising alternative as a clean energy source.

Corresponding author: Dr. Abdellah Benami, Ph.D. in Materials Science and Engineering from IIM-UNAM Mexico, professor of Physics at FST-Errachidia, research fields: plasmonic, nanotchnology and simulation of thin film solar cells.
PV cells have the ability to convert the sun's energy, available in abundance during a major part of the year, directly into electrical power that was used in every day human life. Solar cells are divided into four generations depending on the basic material used and the level of commercial maturity [4]. Silicon based PV cells have been dominating the PV world market for more than 30 years. But the expensive manufacturing technology and waste of energy by producing heat have been pulling back the prospects of PV cells. The reduction of these costs and large-scale applications are achieved by the second generation also called thin film solar cells. Among thin film technologies, Cadmium-Telluride (CdTe) and Copper-Indium-Gallium-Diselenide (CIGS) have been extensively researched for the last several decades and have reached to efficiencies around 22.1 and 23.3\%, respectively [5]. However, the existence of toxic heavy metal (Cd) and high cost of In, Te and Ga elements in these compositions limit their mass production of $\mathrm{PV}$ devices based on CdTe or CIGS materials [6]. In this context, Copper-Zinc-Tin-Sulphide (CZTS) appears to be a very attractive material applied as an absorber in thin film solar cells, regarding the fact that it is made from low cost, non-toxic, high efficiency and earth abundant materials. CZTS is a quaternary p-type 
semiconductor with excellent PV properties such as high absorption coefficient over $10^{4} \mathrm{~cm}^{-1}$ and an optimal direct band gap energy of $1.4-1.5 \mathrm{eV}$ which is within the ideal range for solar energy conversion [7-9].

Thin film CZTS solar cells can be fabricated using many kinds of techniques such as spray pyrolysis, sol-gel sulfurization, electrodeposition, soluble molecular metal salt precursors and nanocrystal-ink-based approaches [10]. In 1988, Ito and Nakazawa discovered for the first time the PV effect in CZTS films prepared by atom beam sputtering with an efficiency of $0.66 \%$ [11]. Wang et al. [12] reported the highest conversion efficiency of $12.6 \%$ of a CZTS obtained by a hydrazine pure solution process. However, all the efficiencies reported until now are still far below the physical limit of about 32\% [13].

Numerical simulation has become an economic and effective way to predict the effect of changes in material properties, measure the potential merits of cell structures and then optimize the structure of devices. Therefore, in this work, we have used the one-dimensional numerical analysis based on Solar Cell Capacitance Simulator (SCAPS-1D) to investigate the performance dependency of a CZTS solar cell as a function of band gap and thickness of absorber layer and temperature. In our simulation study we have used AM $1.5 \mathrm{G}$ solar spectrum with an intensity of 1,000 $\mathrm{W} / \mathrm{m}^{2}$ and temperature between 260 and $360 \mathrm{~K}$.

\section{Materials and Methods}

SCAPS-1D is an one-dimensional solar cell simulation software developed at the department of Electronics and Information Systems of the Gent University, Belgium [14]. Its advantages are that it is fast, interactive, flexible, with an intuitive user interface and can simulate various thin film layers with measurement from everyday PV practice: $\mathrm{J}-\mathrm{V}, \mathrm{QE}$, $\mathrm{C}-\mathrm{V}, \mathrm{C}-\mathrm{f}$ all under a variation of input parameters. The SCAPS software is freely available to the PV research community on request from the authors.
This code is based on the two equations of continuity of the holes and the electrons and the resolution of the Poisson's equation which are used to describe the phenomena of transport in a device-based semiconductor.

In absence of a magnetic field and in one-dimensional case, the Poisson's equation connecting the potential to the densities of the charge carriers is given by Refs. $[15,16]$ :

$$
\frac{\partial^{2} \Psi}{\partial x^{2}}+\frac{q}{\varepsilon}\left[p(x)-n(x)+N_{D}-N_{A}+\rho_{p}-\rho_{n}\right]=0
$$

where $q$ is the electron charge, $\varepsilon$ is the dielectric constant, $N_{A}$ and $N_{D}$ are densities of acceptor-like and donor-like, $\Psi$ is the electrostatic potential $p$ and $n$ are hole and electron concentration, $\rho_{p}$ and $\rho_{n}$ are holes and electrons distribution, respectively. All of these parameters are function of the position coordinate $x$.

Under steady state conditions of illumination, carrier continuity equations are given by:

$$
\begin{aligned}
& \frac{1}{q} \frac{d J_{p}}{d x}=G_{o p}(x)-R(x) \\
& \frac{1}{q} \frac{d J_{n}}{d x}=-G_{o p}(x)+R(x)
\end{aligned}
$$

where $J_{p}$ and $J_{n}$ are the current densities of hole and electron, $G_{\mathrm{op}}(x)$ is the optical generation rate and $R(x)$ is the net recombination from direct and indirect recombination.

CZTS is the $\mathrm{I}_{2}-\mathrm{II}-\mathrm{IV}-\mathrm{VI}_{4}$ quaternary compound semiconductor by substituting the selenium with sulphur, the rare metal indium with zinc and tin in CIS ternary compound. Each component of CZTS is abundant in the earth's crust (Cu: $50 \mathrm{ppm}, \mathrm{Zn}: 75 \mathrm{ppm}$, Sn: $2.2 \mathrm{ppm}, \mathrm{S}: 260 \mathrm{ppm}$ ) and they possess extremely low toxicity. On the other side, in the case of CIS compound, the contents of indium and selenium in the earth's crust are 0.05 ppm or less [9].

The cell structure used in our simulation study is shown in Fig. 1. It consists of the following material layers: $\mathrm{i}-\mathrm{ZnO} / \mathrm{n}-\mathrm{CdS} / \mathrm{p}-\mathrm{CZTS} / \mathrm{Mo}$. p-CZTS and n-CdS are absorber and buffer layers, respectively, that form the p-n junction and constitute the key parts of the 


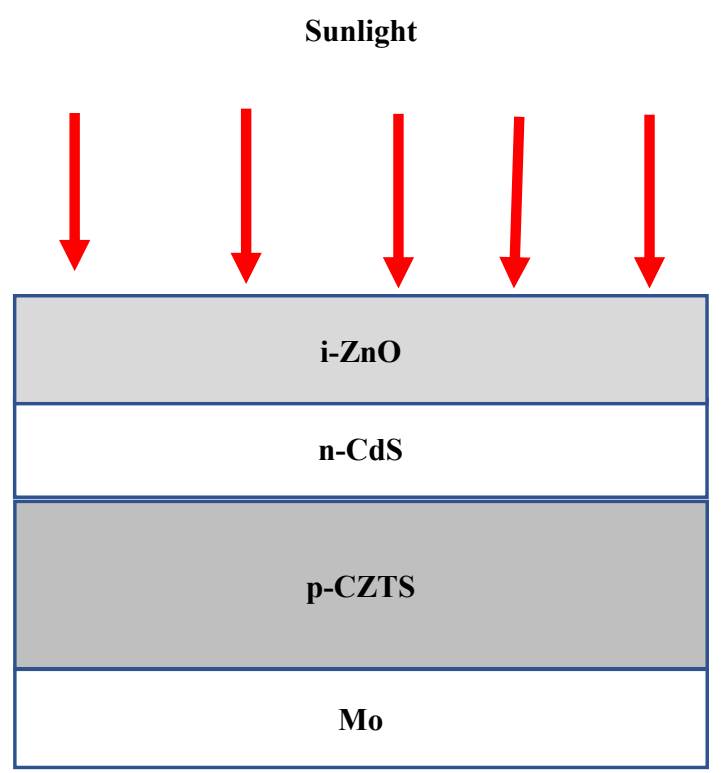

Fig. 1 Structure of CZTS based solar cells.

Table 1 Physical parameters used for numerical analysis of CZTS solar cells.

\begin{tabular}{llll}
\hline Parameters & $\mathrm{i}-\mathrm{ZnO}$ & $\mathrm{n}-\mathrm{CdS}$ & $\mathrm{p}-\mathrm{CZTS}$ \\
\hline$d(\mathrm{~nm})$ & 200 & 50 & $600-5,000$ \\
$E_{g}(\mathrm{eV})$ & 3.3 & 2.4 & $1.4-1.5$ \\
$\chi(\mathrm{eV})$ & 4.4 & 4.2 & 4.5 \\
$\varepsilon_{\mathrm{r}}(1)$ & 9.0 & 10 & 10 \\
$N_{\mathrm{c}}\left(\mathrm{cm}^{-3}\right)$ & $2.2 \times 10^{18}$ & $2.2 \times 10^{18}$ & $2.2 \times 10^{18}$ \\
$N_{\mathrm{v}}\left(\mathrm{cm}^{-3}\right)$ & $1.8 \times 10^{19}$ & $1.8 \times 10^{19}$ & $1.8 \times 10^{19}$ \\
$V_{\mathrm{thN}}$ & $10^{7}$ & $10^{7}$ & $10^{7}$ \\
$V_{\mathrm{thP}}$ & $10^{7}$ & $10^{7}$ & $10^{7}$ \\
$\mu_{\mathrm{n}}\left(\mathrm{cm}^{2} / \mathrm{s}\right)$ & 25 & 25 & 100 \\
$\mu_{\mathrm{p}}\left(\mathrm{cm}^{2} / \mathrm{s}\right)$ & 100 & 100 & 25 \\
$N_{\mathrm{d}}\left(\mathrm{cm}^{-3}\right)$ & $10^{18}$ & $10^{18}$ & 0 \\
$N_{\mathrm{a}}\left(\mathrm{cm}^{-3}\right)$ & 0 & 0 & $1.0 \times 10^{17}$ \\
\hline
\end{tabular}

device. Intrinsic $\mathrm{ZnO}$ and $\mathrm{ZnO}$ layer is used as transparent conductive oxide.

During this research work, to get the result from simulation program uses the various electrical and optical parameters for different layer materials. The basic input parameters used in the simulation were adopted from experimental study, theories, literatures or reasonable estimates in some cases [10, 17-19], which are summarized in Table 1.

\section{Results and Discussion}

Under standard condition, the optimum band gap for a maximum efficiency around $32 \%$ is in the range of 1.2-1.4 eV [13, 20]. For this reason, we have fixed the energy band gap at $1.4 \mathrm{eV}$ and studied the impact of thickness of CZTS absorber layer on cell performance. By varying the thickness of CZTS from 600 to 5,000 $\mathrm{nm}$ with keeping other input parameters like $\mathrm{CdS}$ and $\mathrm{ZnO}$ layers thickness unchanged. Fig. 2 shows the effect of the thickness of CZTS on the cell performance parameters, such as short circuit current density $\left(J_{\text {sc }}\right)$, open circuit voltage $\left(V_{\text {oc }}\right)$, fill factor $(\mathrm{FF})$ and efficiency $(\eta)$. It seems that all the cell performance parameters increase with increasing CZTS thickness. Because, if thickness is increased, then more photons are absorbed, and as a result more electron hole pairs are generated. From Fig. 2, the optimum thickness for CZTS layer is $2,000 \mathrm{~nm}$.

In our simulation, the influence of energy band gap of CZTS on cell performance is also investigated. We kept unchanged the thickness of CZTS and varied the band gap from 1.4 to $1.5 \mathrm{eV}$ and simulation results are shown in Fig. 3. It can be seen that by increasing the band gap of CZTS, $V_{\text {oc }}$ is increased from 0.83 to 0.93 V. Obtained greater $V_{\text {oc }}$ at higher ban gap is due to the

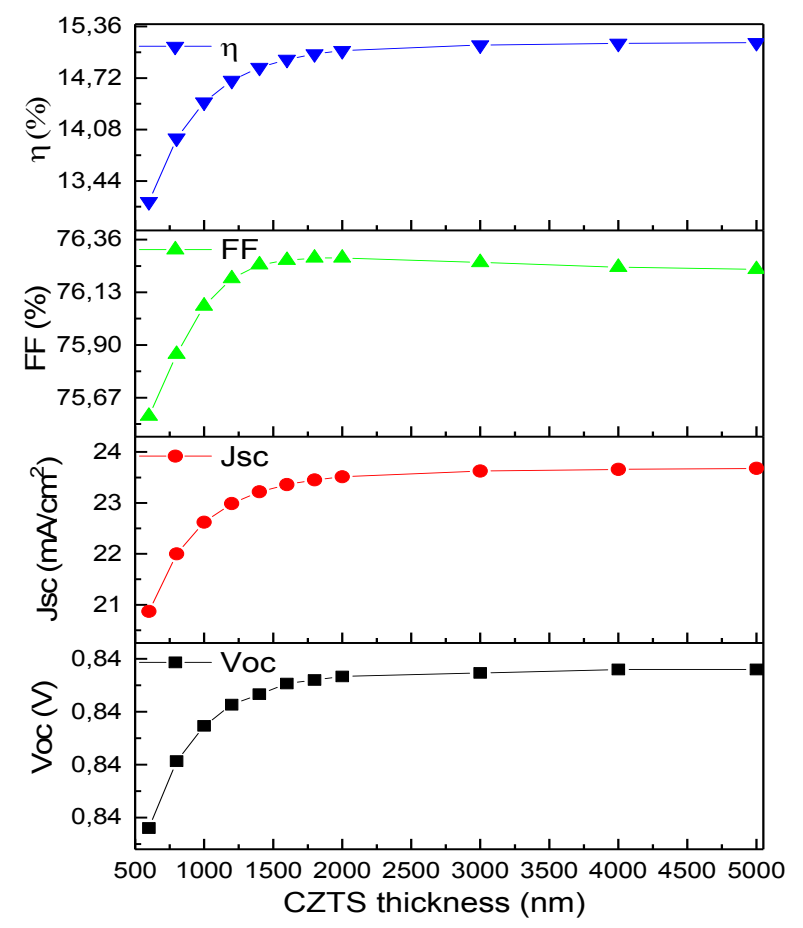

Fig. 2 Effect of variation of CZTS thickness on cell performance. 


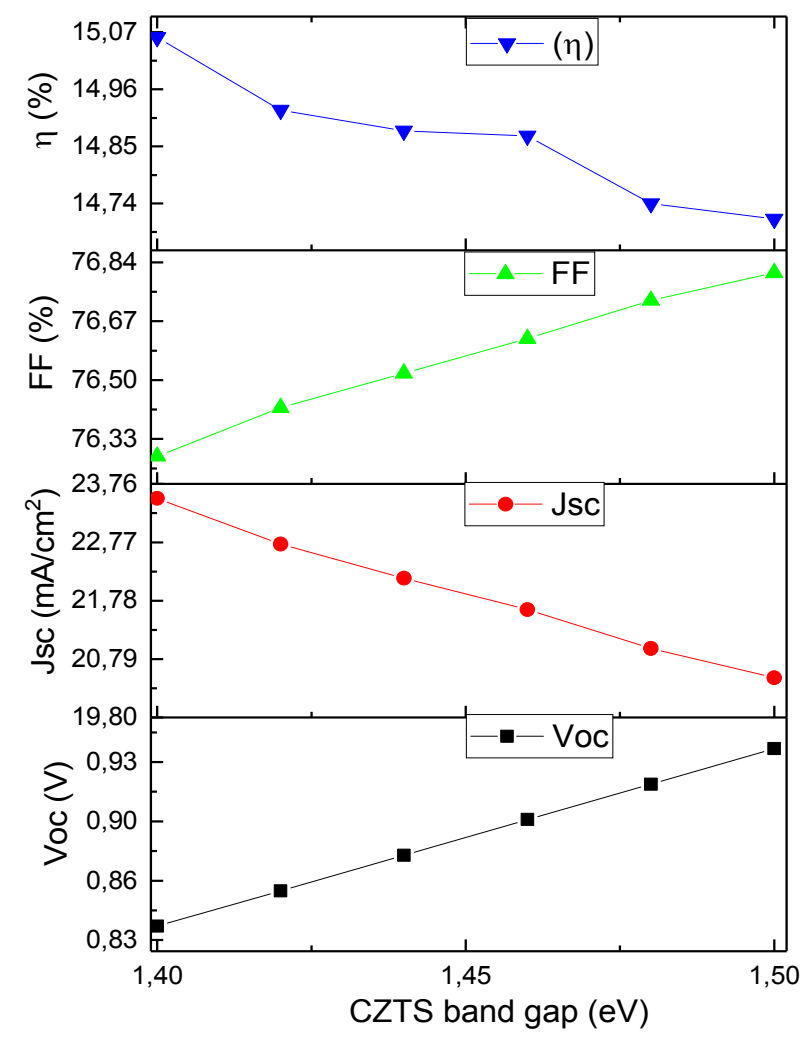

Fig. 3 Effect of the CZTS band gap on cell performance.

larger quasi Fermi energy level splitting. In contrast $J_{\text {sc }}$ decreases drastically with the increase of CZTS band gap, due to the decrease of absorption coefficient. FF follows the same trend as observed in $V_{\text {oc }}$ and enhanced with the increase of band gap from 1.4 to $1.5 \mathrm{eV}$. The increase of FF may be due to the lowering of $J_{\mathrm{sc}}$, that is caused by the absorption loss. The efficiency of the solar cell decreases with the band gap, which can be explained by the creation of defects in the volume of the absorber [21].

\section{Conclusion}

In the present study, we carried out numerical simulation by using SCAPS-1D package to observe the solar cell performance by varying thickness and band gap of CZTS absorber layer. The simulation shows that the optimized thickness and band gap of absorber layer is $2,000 \mathrm{~nm}$ and $1.4 \mathrm{eV}$, respectively. In the range of calculation, the optimal cell properties have been achieved with an efficiency of $15.04 \%$, FF of $76.28 \%, J_{\mathrm{sc}}$ of $23.51 \mathrm{~mA} / \mathrm{cm}^{2}$ and $V_{\mathrm{oc}}$ of $0.84 \mathrm{~V}$. The results above will play a guidance role in fabricating higher efficiency CZTS based thin film solar cells.

\section{References}

[1] Tyagi, H., Agarwal, A. K., Chakraborty, P. R., and Powar, S., eds. 2018. Applications of Solar Energy. Springer Nature Singapore Pte Ltd.

[2] De, S., Bandyopadhyay, S., Assadi, M., Mukherjee, D. A., eds. 2018. Sustainable Energy Technology and Policies A Transformational Journey. Volume 1, Springer Nature Singapore Pte Ltd.

[3] International Energy Agency. 2017. Key World Energy Statistics.

[4] Jayawardena, K. D. G. I., Rozanski, L. J., Mills, C. A., Beliatis, M. J., Nismy, N. A., and Silva, S. R. P. 2013. "Inorganics in Organics Recent Developments and Outlook for 4G." Nanoscale 5: 8411-27.

[5] Green, M. A., Hishikawa, Y., Dunlop, E. D., Levi, D. H., Ebinger, J. H., and Baillie, A. W. Y. H. 2018. "Solar Cell Efficiency Tables.” Prog. Photovoltaics: Res. Appl. 26: 3.

[6] Gueddim, A., Bouarissa, N., Naas, A., Daoudi, F., and Messikine, N. 2018. "Characteristics and Optimization of ZnO/CdS/CZTS Photovoltaic Solar Cell.” Appl. Phys. A 124: 199.

[7] Yang, K.-J., et all. 2016. "A Band-Gap-Graded CZTSSe Solar Cell with $12.3 \%$ Efficiency." J. Mater. Chem. A 4: 10151-8.

[8] Patel, M., Mukhopadhyay, I., and Ray, A. 2012. "Structural, Optical and Electrical Properties of Spray-Deposited CZTS Thin Films under a Non-equilibrium Growth Condition." J. Phys D Appl Phys 45: 445103-13.

[9] Katagiri, H., Jimbo, K., Maw, W. S., Oishi, K., Yamazaki, M., Araki, H., and Takeuchi, A. 2009. "Development of CZTS-Based Thin Film Solar Cells." Thin Solid Films 517: 2455-60.

[10] Kentaro, I. 2015. Copper Zinc Tin Sulfide-Based Thin-Film Solar Cells. New York: John Wiley \& Sons.

[11] Ito, K., and Nakazawa, T. 1988. "Electrical and Optical Properties of Stannite-Type Quaternary Semiconductor Thin Films.” Jpn. J. Appl. Phys. 27: 2094.

[12] Wang, W., Winkler, M. T., Gunawan, O., Gokmen, T., Todorov, T. K., Zhu, Y., and Mitzi, D. B. 2013. "Device Characteristics of CZTSSe Thin-Film Solar Cells with 12.6\% Efficiency." Advanced Energy Materials 4 (7).

[13] Shockley, W., and Queisser, H. J. 1961. "Detailed Balance Limit of Efficiency of pn Junction Solar Cells." $J$. Appl. Phys. 32: 510. 
[14] Burgelman, M., Decock, K., Khelifi, S., and Abass, A. 2013. "Advanced Electrical Simulation of Thin Film Solar Cells." Thin Solid Films 535: 296-301.

[15] Sze, S. M., and Ng, K. K. 2007. Physics of Semiconductor Devices, 3rd ed. New York: John Wiley \& Sons.

[16] Daoudia, A. K., El Hassouani, Y., and Benami, A. 2016. "Investigation of the Effect of Thickness, Band Gap and Temperature on the Efficiency of CIGS Solar Cells through SCAPS-1D." IJETR 8 (3): 71-5.

[17] Frisk, C., Ericson, T., Li, S. Y., et al. 2016. "Combining Strong Interface Recombination with Bandgap Narrowing and Short Diffusion Length in $\mathrm{Cu}_{2} \mathrm{ZnSnS}_{4}$ Device Modelling." Sol. Energy Mater. Sol. Cells 144: 364-70.

[18] Courel, M., Andrade-Arvizu, J. A., and Vigil-Galán, O.
2015. "Loss Mechanisms Influence on $\mathrm{Cu}_{2} \mathrm{ZnSnS}_{4} / \mathrm{CdS}$-Based Thin Film Solar Cell Performance." Solid-State Electron 111: 243-50.

[19] Seol, J. S., Lee, S. Y., Lee, J. C., Nam, H. D., and Kim, K. H. 2003. "Electrical and Optical Properties of $\mathrm{Cu}_{2} \mathrm{ZnSnS}_{4}$ Thin Films Prepared by rf Magnetron Sputtering Process." Sol. Energy Mater. Sol. Cells 75: 155.

[20] Peter, L. M. 2011. "Towards Sustainable Photovoltaics: The Search for New Materials." Philos. Trans. Ser. A: Math. Phys. Eng. Sci. 369: 1840-56.

[21] Rau, U., Schmidt, M., Jasenek, A., Hanna, G., and Schock, H. W. 2011. "Electrical Characterization of $\mathrm{Cu}(\mathrm{In}, \mathrm{Ga}) \mathrm{Se}_{2}$ Thin-Film Solar Cells and the Role of Defects for the Device Performance." Solar Energy Materials and Solar Cells 67 (1-4): 137-43. 